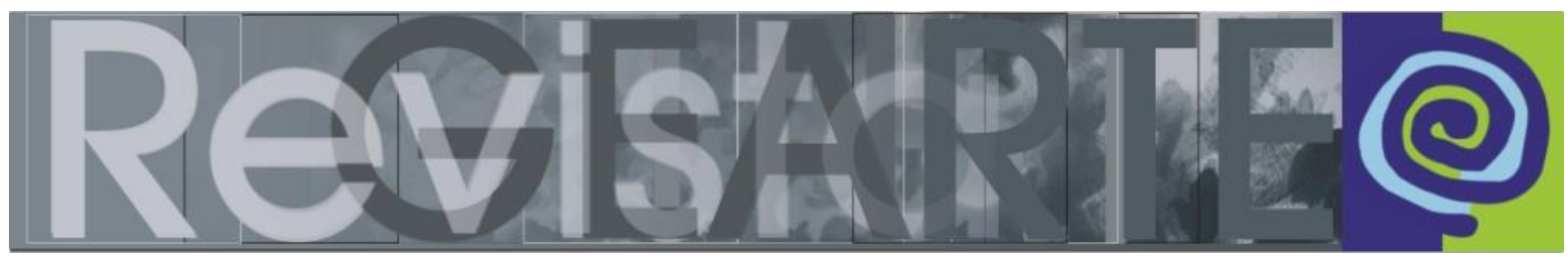

ISSN 2357-9854

\title{
Ensaio Visual: Café com ZMário
}

\author{
José Mário Peixoto Santos - ZMário (Universidade de Brasília \\ — UnB, Brasília/ DF, Brasil)
}

RESUMO - Ensaio Visual: Café com ZMário - O Café com ZMário, assim como a culinária performática e relacional de Rirkrit Tiravanija, é pretexto para a criação do encontro e do próprio texto oral sobre nossas vidas, profissões, amores, desejos, frustrações... A cafeteira, o fogareiro portátil, as xícaras diversificadas e coloridas e, principalmente, a bebida estimulante tornam-se meios e objetos estéticos para a produção de uma obra entre a arte e a vida.

\section{PALAVRAS-CHAVE}

Arte contemporânea. Performance arte. Arte relacional.

ABSTRACT - Visual Essay: Café com ZMário - Café com ZMário as well as the performative cuisine and relational art by Rirkrit Tiravanija is a pretext for the creation of the meeting and the oral text about our lives, professions, loves, desires, frustrations... The coffee machine, the portable stove, the diverse and colorful cups and mainly the stimulating drink become ways and aesthetic objects for producing an art work between art and life.

\section{KEYWORDS}

Contemporary art. Performance art. Relational art.

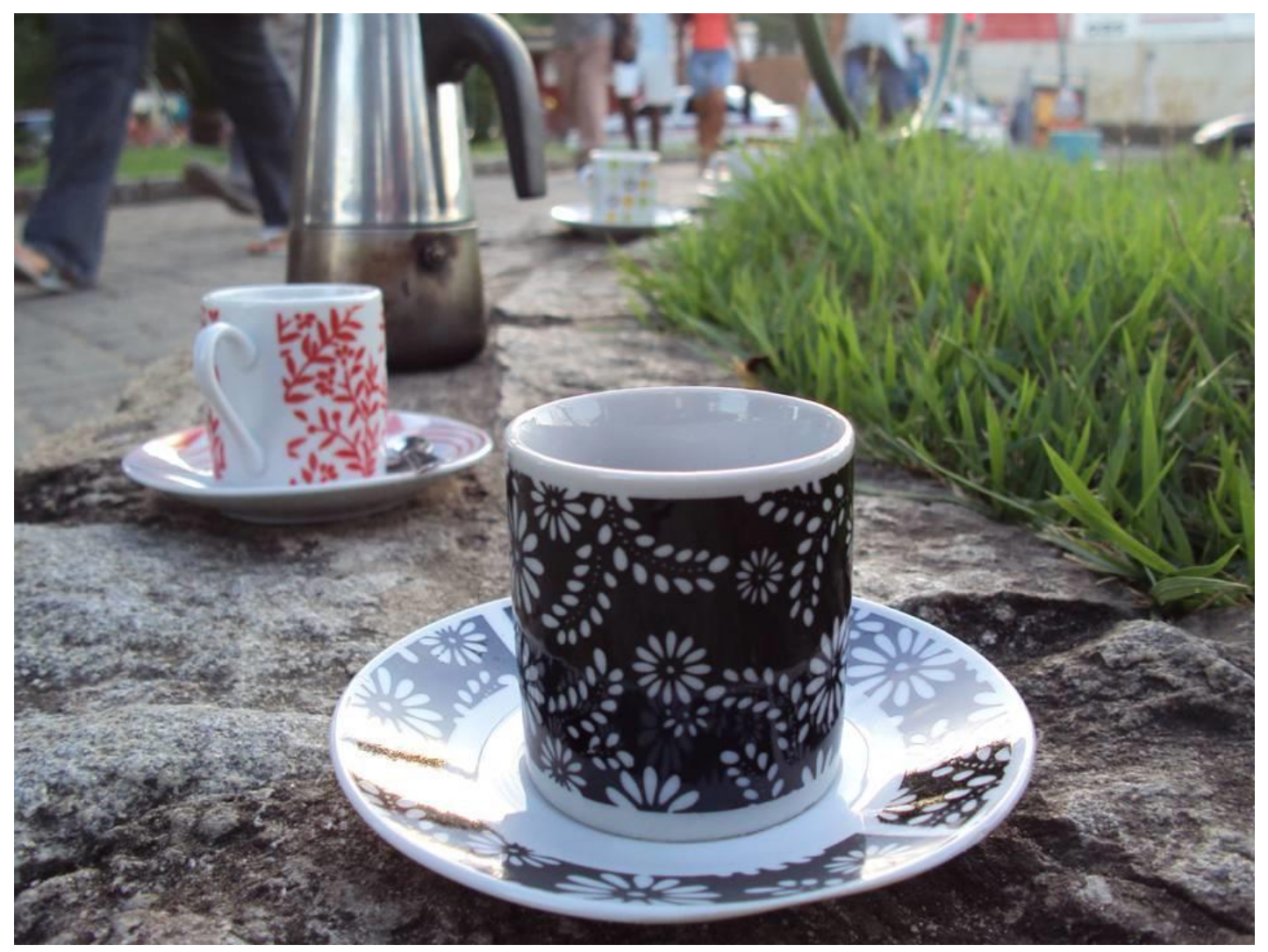

Revista GEARTE, Porto Alegre, v. 4, n. 1, p. 150-155, jan./abr. 2017.

Disponível em: http://seer.ufrgs.br/gearte 

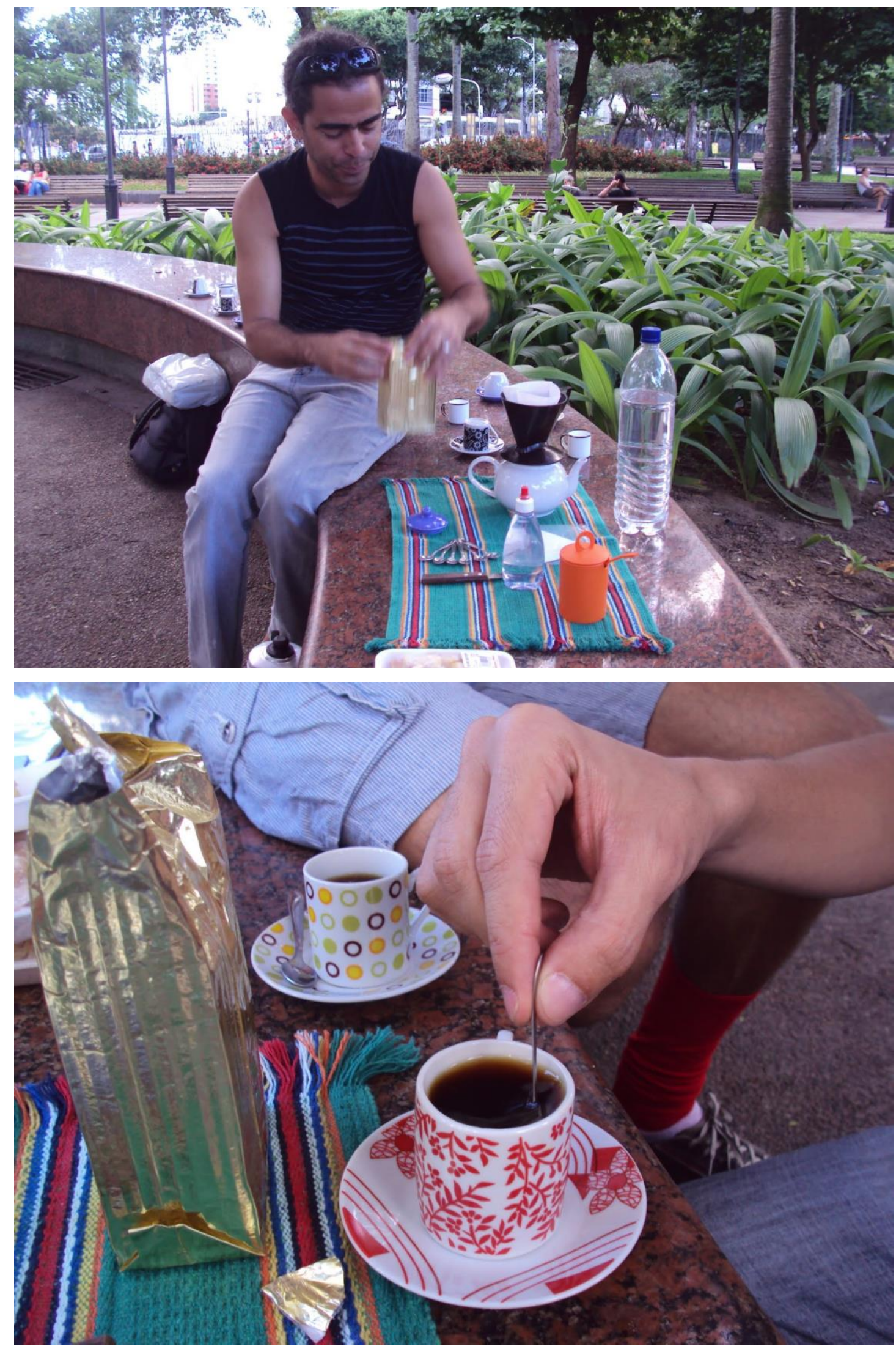

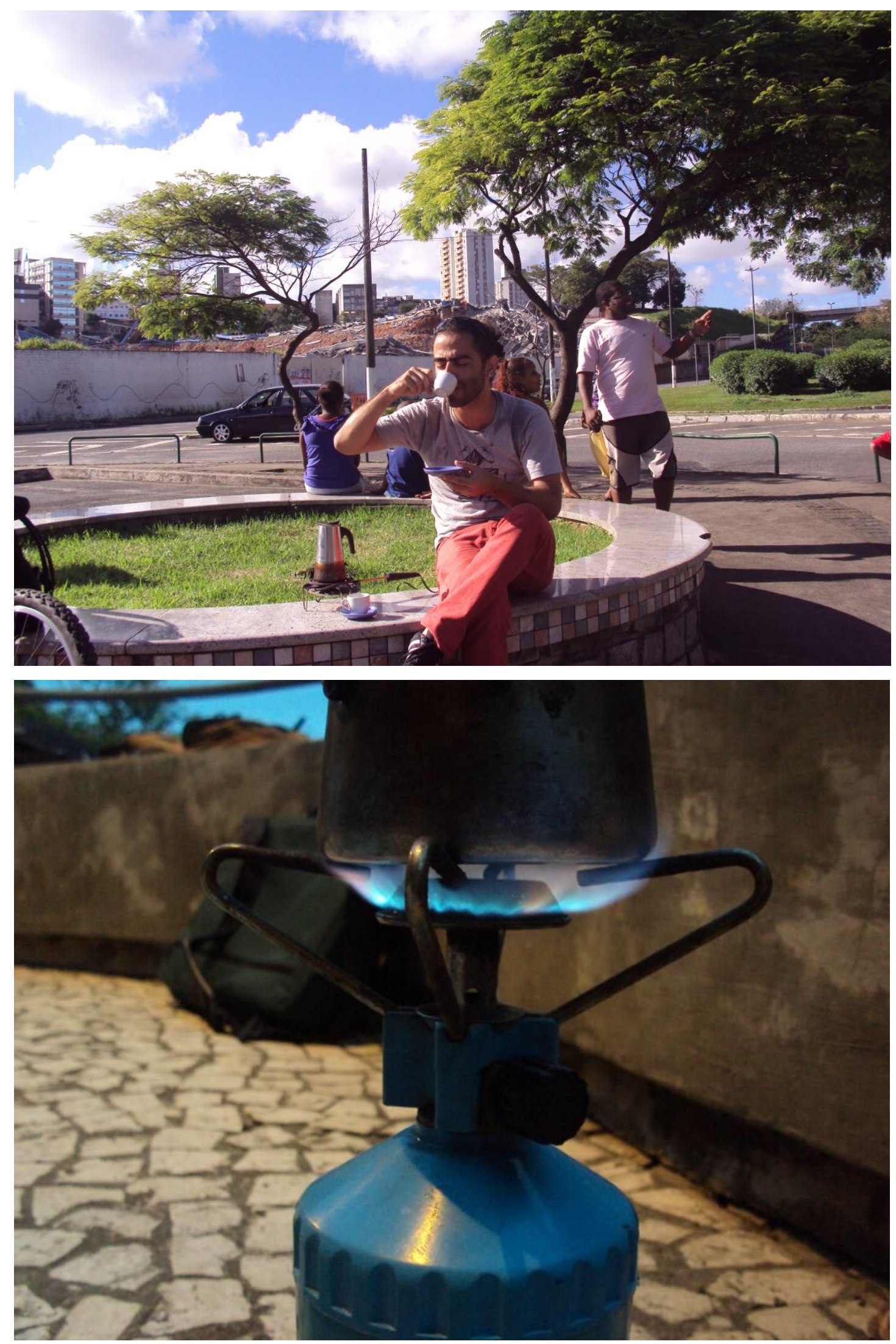

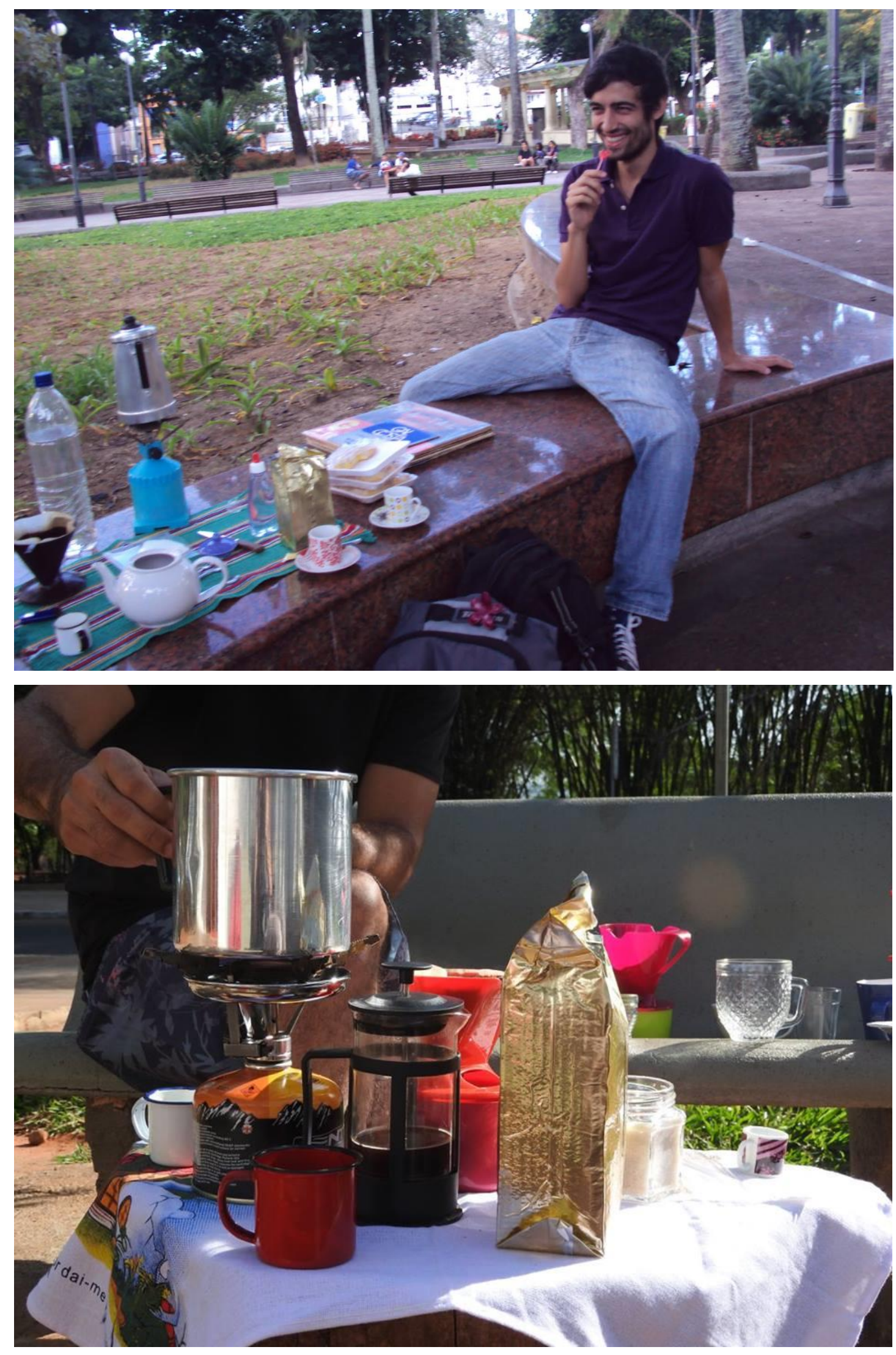

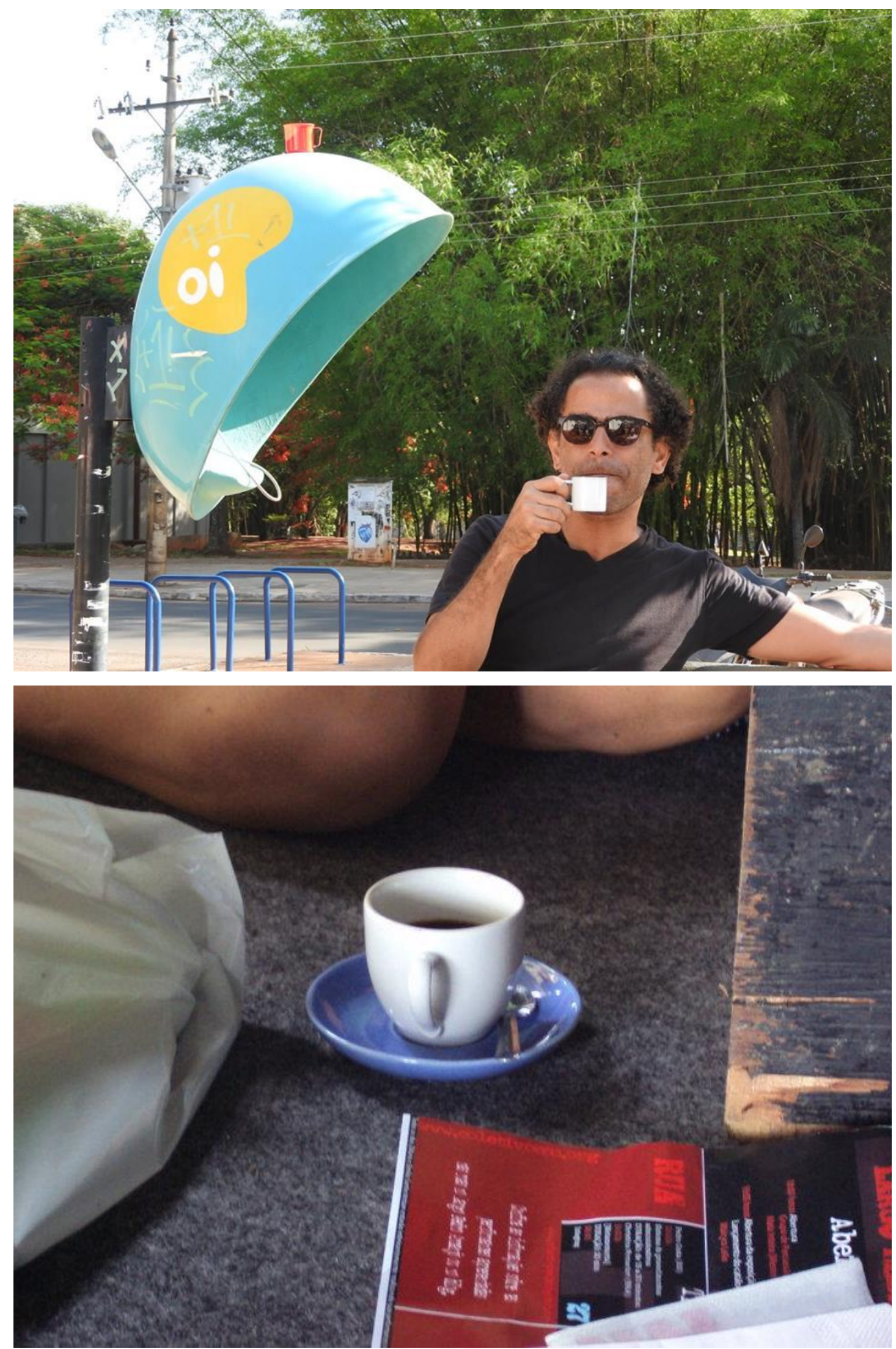
José Mário Peixoto Santos - ZMário

É artista performático, professor e pesquisador da arte da performance. Mestre em Artes Visuais pelo Programa de Pós-Graduação em Artes Visuais (PPGAV) da Escola de Belas Artes da Universidade Federal da Bahia (UFBA), onde pesquisou a produção de Performance Art na cidade de Salvador, Bahia, na linha de pesquisa Teoria e História da Arte. Doutorando em Poéticas Contemporâneas pelo Programa de Pós-Graduação em Arte do Instituto de Artes (IDA-PPG-Arte) da Universidade de Brasília (UnB), onde pesquisa a arte da performance sob a orientação da Profa. Dra. Maria Beatriz de Medeiros. Atualmente, integra o Grupo de Pesquisa Corpos Informáticos da UnB, Brasília-DF.

E-mail: cafecomzmario@gmail.com

Lattes: http://buscatextual.cnpq.br/buscatextual/visualizacv.do?id=K4267453P5

Fotos: ZMário e anônimos

Recebido em 5 de abril de 2017 Aceito em 21 de abril de 2017 